PRAMANA

(C) Indian Academy of Sciences

Vol. 81, No. 6

- journal of

December 2013

physics

p. 1071

\title{
Retraction note: Hydrogenated nanocrystalline silicon germanium thin films
}

\author{
A R M YUSOFF*, M N SYAHRUL and K HENKEL \\ Department of Physics, University Science Malaysia, Penang, Malaysia \\ ${ }^{*}$ Corresponding author. E-mail: abdrashid4@yahoo.com \\ DOI: 10.1007/s12043-013-0515-6; ePublication: 23 February 2013
}

(Pramana - J. Phys. 69(2), 285-300 (2007))

This paper has been withdrawn by Pramana as the editors have determined that the material presented in this paper is a complete copy of the material which has been published by other authors in other journals and reports. 